\title{
Avaliação do desenvolvimento das competências gerais em graduandos de cursos de nutrição
}

\section{Evaluation of the development of general competences in undergraduate courses in nutrition}

\author{
Edilceia Domingues do Amaral Ravazzani', Graciele de Matia', \\ Izabel Meister Coelho ${ }^{3}$, Roberto Zonato Esteves ${ }^{4}$
}

\author{
'Autora para correspondência. Centro Universitário Autônomo do Brasil, Curitiba, Paraná, Brasil. \\ ORCID: 0000-0001-8611-6503. edilceiarav@hotmail.com \\ ${ }^{2}$ Faculdades Pequeno Príncipe, Curitiba, Paraná, Brasil. ORCID: 0000-0002-6538-4346. graciele.matia@gmail.com \\ ${ }^{3}$ Faculdades Pequeno Príncipe, Curitiba, Paraná, Brasil. ORCID: 0000-0002-4904-0746. izamcoelho@gmail.com \\ ${ }^{4}$ Faculdades Pequeno Príncipe, Curitiba, Paraná, Brasil; Universidade Estadual de Maringá, Maringá, Paraná, Brasil. \\ ORCID: 0000-0001-6632-775X. manhabc209@gmail.com
}

RESUMO: As Diretrizes Curriculares Nacionais direcionam a educação para mudanças no processo ensino-aprendizagem, buscam a valorização da formação quando estabelecem em sua estrutura, competências gerais e específicas, enfatizando a importância do acompanhamento pela avaliação sistemática e permanente visando à melhoria na graduação. A presente pesquisa teve por objetivo avaliar o desenvolvimento das competências gerais em graduandos de nutrição. Trata-se de um estudo analítico com abordagem quantitativa e método transversal onde se utilizou um questionário, elaborado e validado por Matia e Coelho (2015) composto por 44 questões, aplicado em estudantes e professores de quatro instituições de ensino por meio do Software Google forms. Para análise descritiva dos dados foram utilizadas medidas de tendência central e medidas de variabilidade e os testes Mann Whitney, Tukey e Teste- $t$ com nível de significância de $p<0,05$, realizadas por meio do Software livre $R$ versão 3.1.1. Obteve-se um total de 210 respostas, sendo 110 de estudantes de ambos os sexos e 100 de professores. A média de idade de estudantes foi de $24,66 \pm 7,41$ anos. A amostra foi composta por predominância de participantes do gênero feminino ( $87,3 \%)$. Na visão dos professores, os estudantes avaliados parecem estar desenvolvendo mais competências e habilidades de Gestão em saúde e Educação em saúde e na visão dos estudantes houve pequeno destaque apenas na Educação em saúde. Conclui-se que os estudantes dos cursos de nutrição envolvidos na pesquisa não estão desenvolvendo as competências profissionais gerais necessárias a formação, apontadas nas diretrizes, em sua totalidade.

PALAVRAS-CHAVE: Competência profissional. Educação baseada em competências. Nutrição. Avaliação educacional.

\begin{abstract}
The National Curricular Guidelines direct education to changes in the teaching-learning process, seek the appreciation of training when they establish in their structure, general and specific competences and emphasize the importance of a systematic and permanent follow-up evaluation aimed at improving graduation. The present research had the objective of evaluating the development of the general competences of undergraduate students of nutrition. An analytical study with a quantitative approach and cross-sectional method using a questionnaire, elaborated and validated by Matia and Coelho (2015) composed of 44 questions, which was applied to students and teachers, from four educational institutions, through the Google forms Software. For the descriptive analysis of the data, we used measures of central tendency and measures of variability and the tests Mann Whitney, Tukey and Test-t, with level of significance of $p<0.05$, realized through Free software $R$ version 3.1.1. A total of 210 answers were obtained, of which 110 were students of both sexes and 100 of teachers. The mean age of students was $24.66 \pm$ 7.41 years. The sample consisted of a predominance of female participants $(87.3 \%)$. In the view of the teachers, the evaluated students seem to be developing more competences and abilities of Management in health and Education in health and in the vision of the students there was small emphasis only in Education in health. It is concluded that the students of the courses of nutrition involved in the research, are not developing the general skills necessary for the training, pointed out in the guidelines, in its entirety.
\end{abstract}

KEYWORDS: Professional competence. Competencybased education. Nutrition. Assessment. 


\section{Introdução}

No Brasil, as Diretrizes Curriculares Nacionais (DCN) dos cursos da área de saúde buscam valorizar a formação, propor mudanças no processo de ensino-aprendizagem e preveem mudanças curriculares que orientam a formação profissional segundo competências gerais e específicas, com ênfase nos princípios do Sistema Único de Saúde (SUS), uma vez que consideram as necessidades de saúde individuais e coletivas para a reorientação do modelo assistencial, valorizam a promoção da saúde e reforçam a necessidade de avaliação sistemática, com o intuito de determinar o incremento de conhecimento na graduação pelos estudantes. ${ }^{1,2}$ Nas últimas décadas, a educação dos profissionais de saúde tem sido repensada, processo resultante das mudanças estruturais do mundo contemporâneo nos mais diversos aspectos, político, econômico, cultural, social e tecnológico. Essas mudanças redirecionam as políticas de educação e saúde, que, por sua vez, resgatam elementos fundamentais para repensar a educação dos profissionais de saúde. ${ }^{3}$

Segundo as DCNs o Nutricionista é o profissional com formação generalista, humanista e crítica, capacitado a atuar em todas as áreas da alimentação e Nutrição com foco na promoção, manutenção e recuperação da saúde e na prevenção de doenças, contribuindo para a melhoria da qualidade de vida, pautado em principios éticos, com reflexão sobre a realidade atual ' ${ }^{1}$. Assim, a prática profissional deve atender a demanda da sociedade por nutricionistas adaptados as constantes mudanças.

A transição do ensino tradicional para um ensino baseado em competências desperta o interesse dos estudiosos pelo assunto e diferentes conceitos de competência foram postulados, a educação baseada em competências está associada ao "ser capaz de". Desta forma, competência pode ser compreendida como um conjunto de atributos e capacidades desenvolvidas pelos indivíduos. ${ }^{4-5} \mathrm{Na}$ área da saúde, competência pode ser entendida como a capacidade de um indivíduo cuidar do outro empenhando seus conhecimentos, habilidades e atitudes na prevenção e promoção da nas diferentes áreas de atuação. ${ }^{5-6}$

Avaliar o desenvolvimento das competências é um desafio, mas a ação é incentivada como um meca- nismo que possibilita $\circ$ acompanhamento da construção do conhecimento. É preciso estabelecer formas de avaliá-las para que melhorias contínuas, nos currículos possibilitem formar profissionais eficientes, conscientes e críticos no trabalho e na sociedade. ${ }^{7-8}$

As Competências Gerais, Atenção à saúde, Tomada de decisão, Comunicação, Liderança, Administração e gerenciamento e Educação permanente são análogas à onze de quatorze outros cursos da área da Saúde. ${ }^{1,9}$

Este trabalho justifica-se uma vez que as $\mathrm{DCN}$ definem a formação em saúde baseada em competências gerais e específicas que contemplem as necessidades sociais da saúde com ênfase no SUS. Ainda destacam que a formação dos profissionais deve contemplar a excelência na promoção da saúde e no reconhecimento dos fatores sociais desencadeadores do processo saúde-doença.

As competências gerais podem ser consideradas um alicerce para o profissional, e por isso avaliá-las se torna importante, pois possibilitaráa proposição de ações aos formadores para sanear os problemas que se apresentarem. $O$ presente estudo buscou avaliar o desenvolvimento das competências gerais em graduandos de Nutrição em Instituições de Ensino Superior pública e particulares em um município do sul do Brasil.

\section{Metodologia}

Trata-se de estudo analítico com abordagem quantitativa de caráter transversal. A amostra foi formada por estudantes e professores do ensino superior vinculados a cursos de Nutrição, reconhecidos e em andamento, situados em um município da região sul do Brasil. Foram incluídos na pesquisa, estudantes devidamente matriculados e professores que ministravam aulas no curso; todos aceitaram participar da pesquisa, assinando o Termo de Consentimento Livre e Esclarecido (TCLE). Foram incluídas na pesquisa instituições públicas e privadas, que foram aqui denominadas por letras de $A$ a $D$, tendo uma participação equivalente das instituições $A, B$ e $D$, mas menor da Instituição $C$. Foram excluídos da pesquisa professores e estudantes que não completaram o preenchimento do instrumento aplicado. 
Para coleta de dados foi utilizado um instrumento para avaliação do desenvolvimento de Competências Gerais para os cursos da área da saúde, desenvolvido e validado por Matia e Coelho, versões $5 A$ e $5 B$, que se apresenta dividido em três dimensões: Atenção à Saúde, Gestão em Saúde e Educação em Saúde. As dimensões foram baseadas nas Diretrizes curriculares para os cursos de Medicina, o qual teve sua diretriz reformulada recentemente. ${ }^{10} \mathrm{O}$ instrumento de coleta de dados autoaplicável é composto por 44 questões e uma escala de medida tipo Likert. Aos estudantes foi aplicado o questionário Versão $5 \mathrm{~A}$ e ao professor um questionário semelhante, em espelho, Versão 5B com os mesmos direcionadores, porém na visão de cada um. Desta forma, para cada estudante respondente houve um questionário preenchido por um professor por meio do qual este procedia a avaliação do estudante.

A aplicação dos instrumentos foi realizada utilizando o Software Google Forms. As respostas foram codificadas, onde a escala Likert foi apresentada em forma numérica de 1 a 5 , onde 1 representa o "discordo totalmente" e 5 "concordo totalmente". Utilizou-se para análise descritiva dos dados, medidas de tendência central e medidas de variabilidade. Os testes de Mann-Whitney, Teste T e Teste Tukey foram aplicados para se verificar se houve evidências para acreditar que valores de um dos grupos foi superior ao outro, para tanto foram considerados, em todos os testes, resultados significativos àqueles valores de $\mathrm{p}<0,05$. As análises estatísticas foram realizadas pelo programa estatístico $R$ versão 3.1.1. O projeto foi encaminhado ao Comitê de Ética em Pesquisa (CEP) CAAE: 53978315.4.0000.5580 e aprovado em 08.04.2016.

\section{Resultados}

Responderam ao questionário 210 estudantes e professores de quatro diferentes instituições de ensino superior (A-D), sendo 110 de estudantes e 100 de professores. Das quatro instituições participantes, três eram privadas e uma pública. Todas apresentavam o curso de Nutrição em funcionamento há mais de 10 anos, utilizavam currículo tradicional e desenvolviam a graduação em 8 semestres. Relativo aos

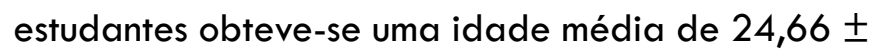
7,41 anos, sendo a idade mínima de 17 anos e a máxima de 55 anos.

A Tabela 1 apresenta dados descritivos das principais características do estudo, expressa em quantidades e percentuais de respondentes em cada categoria das variáveis utilizadas.

Tabela 1. Variáveis descritivas de estudantes dos Cursos de Nutrição da região sul do Brasil, 2016 (continua)

\begin{tabular}{lcc}
\hline Variáveis & Quantidade & Percentual \\
\hline Sexo & 96 & 87.3 \\
Feminino & 14 & 12.7 \\
Masculino & & \\
Instituição de ensino & 30 & 27.3 \\
Instituição A & 34 & 30.9 \\
Instituição B & 34 & 14.5 \\
Instituição C & 16 & 27.3 \\
Instituição D & 30 & 15.5 \\
Período atual & & 17
\end{tabular}




$\begin{array}{lcc}\text { Segundo } & 6 & 5.5 \\ \text { Terceiro } & 9 & 8.2 \\ \text { Quarto } & 23 & 20.9 \\ \text { Quinto } & 19 & 17.3 \\ \text { Sexto } & 14 & 12.7 \\ \text { Sétimo } & 20 & 18.2 \\ \text { Oitavo } & 2 & 1.8\end{array}$

Fonte: Dados do estudo.

Vale salientar que durante a realização da pesquisa nem todos os períodos estavam em curso devido algumas instituições não terem realizado processo seletivo de entrada em todos os semestre, desta forma, obteve-se uma menor participação de estudantes do segundo, terceiro e oitavo períodos.

Ao se avaliar as respostas dadas por estudantes e professores, as Tabela 2 e 3 demonstram os valores médios de escores obtidos das respostas dadas, segundo as três dimensões avaliadas; salientando-se que a média das respostas dadas para a dimensão Gestão em saúde foi a menor atribuída por estudantes e professores,

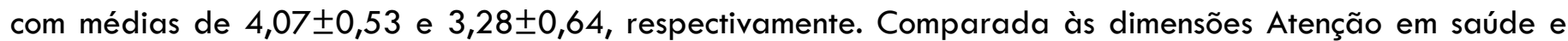
Educação em Saúde, destaca-se ainda que a avaliação dos professores em todas as dimensões foi menor do que as avaliações realizadas pelos estudantes.

Tabela 2. Média, mediana, mínimo, máximo e Desvio-Padrão para as três dimensões do questionário aplicado aos estudantes dos Cursos de Nutrição da região sul do Brasil, 2016.

\begin{tabular}{|c|c|c|c|c|c|c|c|c|}
\hline & $\mathbf{N}$ & Min & $1^{\circ}$ Quartil & Mediana & $3^{\circ}$ Quartil & $\operatorname{Max}$ & Média & DP \\
\hline $\begin{array}{l}\text { Atenção à } \\
\text { saúde }\end{array}$ & 110 & 2.889 & 3.889 & 4.222 & 4.444 & 5 & 4.19 & 0.44 \\
\hline $\begin{array}{l}\text { Gestão em } \\
\text { saúde }\end{array}$ & 110 & 2.292 & 3.75 & 4.125 & 4.49 & 5 & 4.07 & 0.53 \\
\hline $\begin{array}{l}\text { Educação } \\
\text { em saúde }\end{array}$ & 110 & 3.273 & 4.182 & 4.455 & 4.727 & 5 & 4.44 & 0.4 \\
\hline Geral & 110 & 2.682 & 3.892 & 4.193 & 4.5 & 5 & 4.19 & 0.43 \\
\hline
\end{tabular}

Fonte: Dados do estudo. 
Tabela 3. Média, mediana, mínimo, máximo e Desvio-Padrão para as três dimensões do questionário aplicado aos professores dos Cursos de Nutrição da região sul do Brasil, 2016

\begin{tabular}{|c|c|c|c|c|c|c|c|c|}
\hline & $\mathbf{N}$ & Min & $1^{\circ}$ Quartil & Mediana & $3^{\circ}$ Quartil & $\operatorname{Max}$ & Média & DP \\
\hline $\begin{array}{l}\text { Atenção à } \\
\text { saúde }\end{array}$ & 100 & 2 & 3 & 3.611 & 4.111 & 4.778 & 3.55 & 0.67 \\
\hline $\begin{array}{l}\text { Gestão } \\
\text { em saúde }\end{array}$ & 100 & 2.25 & 2.781 & 3.167 & 3.677 & 4.708 & 3.28 & 0.64 \\
\hline $\begin{array}{l}\text { Educação } \\
\text { em saúde }\end{array}$ & 100 & 2.091 & 3.091 & 3.636 & 4.295 & 5 & 3.72 & 0.72 \\
\hline Geral & 100 & 2.295 & 2.955 & 3.364 & 3.926 & 4.795 & 3.44 & 0.62 \\
\hline
\end{tabular}

Fonte: Dados do estudo.

Diferenças significativas podem ser observadas na Tabela 4, onde a "Instituição A" foi marcada como aquela que apontou melhores escores na avaliação de seus estudantes na dimensão Educação em saúde (D3).

Tabela 4. Teste de Tukey para avaliar a existência de diferença significativa em comparações específicas, dos questionários aplicados em Cursos de Nutrição da região sul do Brasil, 2016.

\begin{tabular}{lllll}
\hline Pares de instituições & D1 & D2 & D3 & Geral \\
\hline "Instituiçãa B" - "Instituição A" & -0.3 & -0.24 & -0.4 & -0.31 \\
"Instituição C" - "Instituição A" & -0.46 & -0.25 & $-0.82^{*}$ & -0.51 \\
"Instituição D" - "Instituição A" & -0.36 & -0.31 & $-0.58^{* *}$ & $-0.41^{*}$ \\
"Insituição C" - "Instituição B" & -0.15 & -0.01 & -0.42 & -0.2 \\
"Instituição D" - "Instituição B" & -0.05 & -0.07 & -0.18 & -0.1 \\
"Instituiçãa D" - "Instituição C" & 0.1 & -0.06 & 0.25 & 0.1 \\
\hline
\end{tabular}

Fonte: Dados do estudo.

Teste de Tukey

$* *$ Indica p valor $<0,001$

* Indica p valor $<0,05$

Legenda:

D1 - Dimensão Atenção à saúde

D2 - Dimensão Gestão em saúde

D3 - Dimensão Educação em Saúde

As respostas dos graduandos que se encontravam nos quatro primeiros semestre (dois primeiros anos) foram comparadas estatisticamente com aqueles que já estavam na metade final do curso (dois últimos anos). As análises dos questionários respondidos pelos estudantes estão expressas na Tabela 5, sendo demonstrados resultados para cada questão, dimensão e também na avaliação geral.

Ao se observar a tabela percebe-se que houve diferença significativa apenas em algumas questões nas três dimensões. 


\begin{tabular}{|c|c|c|c|c|}
\hline \multirow[b]{2}{*}{ Dimensão } & \multicolumn{2}{|c|}{ Estudantes } & \multicolumn{2}{|c|}{ Professores } \\
\hline & $\begin{array}{l}\text { Média (DP) } \\
1^{\circ} \text { e } 2^{\circ} \text { Anos }\end{array}$ & $\begin{array}{c}\text { Média (DP) } \\
3^{\circ} \text { e } 4^{\circ} \text { Anos }\end{array}$ & $\begin{array}{l}\text { Média (DP) } \\
1^{\circ} \text { e } 2^{\circ} \text { Anos }\end{array}$ & $\begin{array}{l}\text { Média (DP) } \\
3^{\circ} \text { e } 4^{\circ} \text { Anos }\end{array}$ \\
\hline D1 & $4.11(0.5)$ & $4.26(0.36)$ & $3.42(0.57)$ & $3.69(0.75)^{*}$ \\
\hline Q1.1 & $4.09(0.84)$ & $4.36(0.59)$ & $3.82(0.74)$ & $3.9(1.05)$ \\
\hline Q1.2 & $3.78(0.92)$ & $4.09(0.73)$ & $3.39(0.92)$ & $3.61(1.22)$ \\
\hline Q1.3 & $3.98(0.89)$ & $4.09(0.73)$ & $2.82(1.01)$ & $3.73(0.93)^{*}$ \\
\hline Q1.4 & 4.29 (0.69) & $4.2(0.78)$ & $3.33(0.89)$ & $3.84(0.94)^{*}$ \\
\hline Q1.5 & $4.24(0.82)$ & $4.6(0.74)^{*}$ & $3.59(0.83)$ & $3.86(0.94)$ \\
\hline Q1.6 & $3.93(0.96)$ & $4.07(0.77)$ & $3.22(0.78)$ & $3.53(0.94)^{*}$ \\
\hline Q1.7 & $4.33(0.72)$ & $4.49(0.69)$ & $3.33(0.77)$ & $3.76(0.8)^{*}$ \\
\hline Q1.8 & $4.07(0.88)$ & $3.87(0.98)$ & $3.82(0.77)$ & $3.41(1.04)^{*}$ \\
\hline Q1.9 & $4.27(0.85)$ & $4.6(0.6)^{*}$ & $3.47(0.64)$ & $3.55(0.71)$ \\
\hline D2 & $3.98(0.55)$ & $4.16(0.5)$ & $3.03(0.48)$ & $3.53(0.69)^{*}$ \\
\hline Q2.1 & $4.22(0.85)$ & $4.13(0.75)$ & $3.24(0.97)$ & $3.82(1.13)^{*}$ \\
\hline Q2.2 & 3.75 (1.09) & $4.11(0.94)$ & $3.35(0.77)$ & $3.67(0.83)$ \\
\hline Q2.3 & $3.82(0.92)$ & $4.18(0.86)^{*}$ & $3.12(0.65)$ & $3.69(0.82)^{*}$ \\
\hline Q2.4 & $4.04(0.94)$ & $4.29(0.71)$ & $3.1(0.46)$ & $3.45(0.77)^{*}$ \\
\hline Q2.5 & 4.05 (0.97) & $4.18(0.98)$ & $3.08(0.48)$ & $3.41(0.61)^{*}$ \\
\hline Q2.6 & $4.07(0.94)$ & $4.27(0.95)$ & $3.02(0.58)$ & $3.41(0.67)^{*}$ \\
\hline Q2.7 & $4.47(0.81)$ & $4.67(0.7)$ & $3.43(0.9)$ & $4.29(0.79)^{*}$ \\
\hline Q2.8 & $3.96(1.1)$ & $4.11(1.01)$ & $2.96(1.06)$ & $3.51(1.21)^{*}$ \\
\hline Q2.9 & $4.4(0.78)$ & $4.58(0.74)$ & $2.96(1.06)$ & $3.59(1.22)^{*}$ \\
\hline Q2.10 & $4.15(0.78)$ & $4.25(0.67)$ & $3.18(0.77)$ & $3.51(0.87)^{*}$ \\
\hline Q2.11 & $4.05(0.85)$ & $4.05(0.91)$ & $3.18(0.79)$ & $3.41(0.96)$ \\
\hline Q2.12 & $4.65(0.52)$ & $4.78(0.53)$ & $3.43(0.85)$ & 4 (0.79)* \\
\hline Q2.13 & $4.53(0.54)$ & $4.64(0.65)$ & $3.47(1.05)$ & $3.94(1.16)^{*}$ \\
\hline Q2.14 & $4.13(0.75)$ & $4.45(0.74)^{*}$ & $3.25(0.8)$ & $3.61(1.08)$ \\
\hline Q2.15 & $3.67(0.94)$ & $3.98(0.91)$ & $2.78(0.64)$ & $3.33(0.88)^{*}$ \\
\hline Q2.16 & $3.58(1.01)$ & $3.85(1.03)$ & $2.39(0.9)$ & $3.29(0.74)^{*}$ \\
\hline Q2.17 & $3.55(0.96)$ & $3.78(1.01)$ & $2.41(0.88)$ & $3.29(0.79) *$ \\
\hline Q2.18 & $3.69(0.88)$ & $3.89(0.92)$ & $2.49(0.9)$ & $3.37(0.76) *$ \\
\hline Q2.19 & 3.71 (0.96) & $3.75(1.02)$ & $2.75(0.82)$ & $3.41(0.91)^{*}$ \\
\hline Q2.20 & $4.04(0.96)$ & $4.31(0.86)$ & $2.98(0.58)$ & $3.47(0.89)^{*}$ \\
\hline Q2.21 & $4.09(0.97)$ & $4.24(0.82)$ & $3.02(0.37)$ & $3.31(0.82)^{*}$ \\
\hline Q2.22 & 4.02 (0.89) & $4.13(0.77)$ & $3.22(0.73)$ & $3.63(1.07)^{*}$ \\
\hline
\end{tabular}


Tabela 5. Média e desvio padrão das dimensões e questões, por ciclos, dos questionários aplicados aos estudantes e professores dos Cursos de Nutrição da região sul do Brasil, 2016 (conclusão)

\begin{tabular}{ccccc} 
Q2.23 & $3.84(1.01)$ & $4.02(0.93)$ & $3.35(0.98)$ & $3.76(0.85)^{*}$ \\
Q2.24 & $3.07(1.12)$ & $3.11(1.2)$ & $2.51(1.03)$ & $2.69(1.1)$ \\
D3 & $4.34(0.45)$ & $4.55(0.32)^{*}$ & $3.56(0.56)$ & $3.9(0.82)^{*}$ \\
Q3.1 & $3.85(1.1)$ & $4.44(0.63)^{*}$ & $3.41(0.88)$ & $4.1(0.96)^{*}$ \\
Q3.2 & $4.09(0.99)$ & $4.13(0.72)$ & $3.69(0.95)$ & $3.84(1.26)$ \\
Q3.3 & $4.11(0.88)$ & $4.16(0.81)$ & $3.43(0.85)$ & $3.65(1.27)$ \\
Q3.4 & $4.11(0.88)$ & $4.53(0.66)^{*}$ & $3.61(0.92)$ & $4.14(1.08)^{*}$ \\
Q3.5 & $4.42(0.81)$ & $4.69(0.57)$ & $3.75(0.8)$ & $4.24(0.72)^{*}$ \\
Q3.6 & $4.18(0.94)$ & $4.36(0.78)$ & $3.43(0.61)$ & $3.49(1.16)$ \\
Q3.7 & $4.64(0.56)$ & $4.76(0.54)$ & $3.35(0.66)$ & $3.63(1.13)^{*}$ \\
Q3.8 & $4.55(0.63)$ & $4.76(0.54)^{*}$ & $3.33(0.62)$ & $3.67(1.03)^{*}$ \\
Q3.9 & $4.47(0.66)$ & $4.78(0.5)^{*}$ & $3.31(0.58)$ & $3.73(1)^{*}$ \\
Q3.10 & $4.58(0.69)$ & $4.69(0.69)$ & $3.76(0.76)$ & $3.98(1.07)$ \\
Q3.11 & $4.75(0.52)$ & $4.69(0.63)$ & $4.04(0.72)$ & $4.37(1.05)^{*}$ \\
\hline Geral & $4.14(0.44)$ & $4.32(0.33)^{*}$ & $3.34(0.5)$ & $3.71(0.7)^{*}$ \\
\hline
\end{tabular}

Fonte: Dados do estudo.

Valor de $\mathrm{p}$ correspondente ao resultado do teste $t$ ou de Mann-Whitney.

* Valor $\mathrm{p}<0,05$ indica diferença significativa

Legenda:

Q - Questão

D1 - Dimensão Atenção à saúde

D2 - Dimensão Gestão em saúde

D3 - Dimensão Educação em Saúde

Para professores, estudantes dos últimos períodos dos cursos apresentam melhor escore em relação àqueles nos períodos iniciais para dimensão Gestão em saúde seguida da dimensão Educação em saúde. A dimensão Gestão em saúde contempla ações de gerenciamento (equipe, recursos físicos e materiais), trabalho em equipe, resolução de problemas (resolutividade em situações conflituosas), tomada de decisão e liderança. Este resultado pode apontar que os cursos avaliados buscam a formação técnica em detrimento do conhecimento e do desenvolvimento de habilidades necessárias à formação competente e integral do profissional. Resultados significativos podem ser observados na avaliação geral onde podem ser verificados que quase a totalidade das questões apresenta resultados estatísticos significativos $(p<0,05) \circ$ que pode demonstrar que na visão dos docentes os estudantes estão gradativamente desenvolvendo as competências gerais ao longo da formação, uma vez que o escore pontuado final apresenta-se maior que $\circ$ inicial.

\section{Discussão}

A competência pode ser verificada quando se observa a execução de uma tarefa e é aprimorada no dia a dia, no processo de ensino-aprendizagem e na vivência dos sujeitos. Não é apenas um conhecimento adquirido; possuir conhecimento e habilidades não significa ser competente, pois é possível ter conhecimento sem mesmo saber aplicá-lo. A competência profissional é construída por meio de 
processos de aprendizagem que estão influenciados por conjuntos de capacidades humanas: 0 conhecimento (informação - saber o quê e saber o porquê), habilidades (técnicas, capacidade e saber como) e atitudes (querer fazer, identidade e determinação), estas dimensões quando desenvolvidas geram a capacidade aos indivíduos de atuar de maneira competente. ${ }^{11-12}$

No campo da saúde, o desenvolvimento de competências implica na articulação dos diferentes saberes para que se construa uma prática que esteja pautada não apenas na aquisição de conhecimentos, mas na incorporação de habilidades e atitudes pessoais que possam, na prática, transformar a realidade da saúde, principalmente no âmbito do SUS e contribuir para a elevação da qualidade de saúde da população. Nesta ótica, a gestão na saúde passa a ter importância equivalente à formação técnico-científica. ${ }^{13,14}$ Oliveira et al. ${ }^{13}$ traz à tona a discussão de que muitos cursos de formação em saúde têm se mostrado alheios à organização da gestão e ao debate crítico sobre os sistemas que estruturam o cuidado em saúde. Ressaltam ainda, que as instituições formadoras mantêm um ensino dominado por modelos conservadores que estão voltados e focados no domínio técnico-científico da profissão.

A educação em saúde está atrelada ao conceito de promoção da saúde e pode ainda ser considerada uma estratégia de promoção à saúde, visando conscientizar de forma individual ou coletiva a população, colaborando na elevação do bem estar físico e mental, ambiental, pessoal e social ${ }^{14}$. Profissionais de saúde devem estar aptos a orientar indivíduos em todos os níveis e em qualquer ciclo da vida.

O nutricionista é o profissional da saúde responsável pela educação para a alimentação saudável. A ação do profissional, neste contexto, exige a confrontação de novas práticas com as representações sociais dos alimentos e seus significados para os sujeitos do processo educativo. $O$ desafio também está em se contemplar as necessidades de saúde, com ênfase nas demandas da sociedade e do SUS. ${ }^{15,16}$ Cabe ao docente estimular 0 estudante a se manter atualizado, aplicar comunicação efetiva para estar plenamente capacitado na educação em saúde, e assim possa cumprir com atribuições de educador em saúde de forma competente.
Considerando os resultados e refletindo sobre a necessidade do desenvolvimento das competências acredita-se que sejam necessárias mudanças profundas, que devem ser feitas de forma progressiva. Vale ressaltar que nenhum dos cursos avaliados apresenta em seus currículos registro de uso de metodologias ativas de forma sistemática, como estratégias de ensino-aprendizagem, ficando a prática delimitada ao período de estágios obrigatórios que acontecem no final do curso. Desta forma, acredita-se que implementar metodologias ativas seja necessário, mas elas ainda são um desafio para - corpo docente que vivenciou em sua formação a metodologia formal. ${ }^{17}$

As DCNs de Nutrição em seu artigo 9 destacam que - projeto pedagógico deve ser "[...] centrado no estudante como sujeito da aprendizagem e apoiado no professor como facilitador e mediador do processo ensino-aprendizagem"1. Isto aponta para a necessidade de se repensar a formação profissional, independente da instituição.

As metodologias ativas não podem ser meramente aplicadas sem que exista clareza dos objetivos de aprendizagem pretendidos. Para Mitre ${ }^{11}$ quando se objetiva a busca de estudantes mais proativos, é necessário se adotar atividades cada vez mais complexas, isto é, atividades que envolvam a tomada de decisão pelos estudantes, sempre acompanhadas pela avaliação dos resultados de cada um, proporcionando $\circ$ feedback de todas elas. Manter - currículo e incluir metodologias ativas como, por exemplo, "sala de aula invertida", "problematização", "Team Based Learning - TBL" entre outras, como estratégias de ensino-aprendizagem, proporciona ao discente maior motivação pois, diante do problema apresentado ele busca solucionar os impasses e assim promover o seu próprio desenvolvimento. Focar na prática profissional ajuda a pressionar as instituições de ensino a repensar seus currículos e processos utilizados na avaliação, possibilitando assim a reorientação do planejamento educacional a partir das competências desejáveis para seus egressos. ${ }^{4}$

A construção de competências, teoricamente, é um processo indefinido que pode e deve ser contínuo, devido as mudanças constantes do mundo, no que se refere às transições epidemiológicas, demográficas, dietéticas e nutricionais e tecnológicas, levando 
os profissionais bem como as instituições a enfrentarem novos e constantes desafios na formação. Desta forma, não pode existir um único método, ou seja, um único meio de capacitação. Esta capacitação não deve ser entendida como apenas um "projeto" que termina quando a graduação é finalizada, mas um componente central do processo chamado formação. ${ }^{12}$ Deve-se ter em mente que a competência do docente não pode ser transmitida ao estudante, ela deve ser construída de forma ativa. Os modelos formativos propostos são apenas uma referência para o desenvolvimento das competências dos estudantes: cada sujeito imprime sua marca pessoal ao seu processo de aprendizagem, quando ele é agente ativo de sua formação.

Estudantes devem considerar a necessidade constante da busca do conhecimento, valorizando o momento de sala de aula e a vivência prática mas comprometido com seu próprio aprendizado e educação permanente. A educação permanente vem de encontro as Diretrizes curriculares dos cursos de graduação em saúde, busca a formação de um profissional crítico, que seja capaz de aprender a aprender, de trabalhar em equipe e que leva em conta a realidade social o que possibilita em atendimento humano e de qualidade. Ela põe em análise o cotidiano do trabalho ou mesmo da formação em saúde, a educação permanente, constitui uma estratégia que possibilita uma formação realmente sintonizada com as necessidades da saúde pública brasileira. ${ }^{13,18}$

Há consenso na literatura cientifica que é preciso avaliar o desenvolvimento de competências, isto é, se faz necessário observar o desempenho do estudante na prática, para se observar o "nível fazer". Neste sentido, o olhar do professor é importante mas, como em outros cursos, na Nutrição é muito difícil o professor acompanhar a atuação prática, ou seja, o momento do atendimento. Então outros métodos subjetivos de avaliação devem ser implementados, lembrando sempre que o feedback é parte essencial da avaliação educacional. ${ }^{19}$

É importante refletir que apenas alcançar o diploma não garante que as competências estejam dominadas na sua integralidade, uma vez que sua construção se inicia na graduação, mas na atuação profissional elas se fundamentam, pois estão sendo forjadas na prática isto é, na vivência que o dia a dia proporciona. Compreender $\odot$ processo de desenvolvimento de competências é estar de acordo com as situações, experiências vividas e aprendizagens transformadas em conhecimentos e habilidades que, por sua vez, são a base para a formação de atitudes, construindo a capacidade de atuar.

Ao se considerar esta proposição, pode-se ressaltar a importância da prática na vida acadêmica: ela favorece o aprendizado em diferentes ambientes, ambiente este que muitas vezes não podem ser reproduzidos em sala de aula. A vivência proporciona um aprendizado significativo.

As instituições de ensino e os gestores dos cursos precisam estar atentos às mudanças atuais nos cenários de ensino. Uma vez que o desenvolvimento de competências apresenta-se como uma nova perspectiva para a formação dos profissionais de saúde, ela pode, além de incentivar a reflexão crítica, responder às exigências impostas pelos cenários de mudanças sociais e favorecer o desenvolvimento da cidadania. ${ }^{20}$ Para responder aos desafios atuais do trabalho em saúde, faz-se necessário refletir sobre a formação e sobre o perfil de competências desejado aos profissionais da saúde, com enfoque não apenas no conhecimento técnico especializado, mas, principalmente, nas habilidades e atitudes a serem desenvolvidas em prol da saúde da população. Não existe um "molde" ou mesmo uma "forma" de agir: as realidades são diferentes, os problemas são diversos e estar capacitado tecnicamente é importante, reconhecendo os problemas de saúde no âmbito biológico, mas sabendo intervir considerando as peculiaridades individuais e os problemas alimentares no contexto social, político, ambiental e cultural. Assim, percebe-se que este novo cenário tem exigido que os novos nutricionistas tenham plena consciência e reflitam mais profundamente quanto ao seu papel como profissional da saúde, que deve estar comprometido com a promoção de práticas e hábitos alimentares saudáveis visando a realização do Direito Humano à Alimentação Adequada e a garantia da Soberania e Segurança Alimentar e Nutricional no Brasil. ${ }^{6}$ Historicamente, já passamos por críticas da classe empregadora sobre a produção deficiente de trabalhadores qualificados para suprir a demanda do mercado de trabalho, como se as instituições formadoras estivessem colocando no mercado de trabalho um produto. ${ }^{18}$ Atualmente formar profissionais competentes está muito distante 
do que se fazia, mecanicamente, em um passado não tão distante; profissionais "completos" e com o perfil desejado, precisam apresentar habilidades além das técnicas.

O estágio supervisionado atualmente pode ser considerado uma das principais experiências vivenciadas pelos acadêmicos durante a graduação em Nutrição. Este se torna um momento que instiga o estudante a desenvolver as competências gerais propostas, uma vez que neste ambiente é necessário que em diferentes momentos ele tenha que adotar atitudes de liderança, tomar decisões diante de situações reais, demonstrar sua proatividade, exercer a comunicação, entre outras das competências gerais requeridas pelas Diretrizes Curriculares Nacionais. Neste ambiente de aprendizado, o estudante precisa planejar suas ações, aprender a lidar com a flexibilidade diante das decisões tomadas e trabalhar em equipe, conforme lida com situações diversas e aprende a enfrentar as exigências do mercado de trabalho e sua realidade. ${ }^{9}$ O papel do docente é de extrema relevância. Ele se torna o incentivador, aquele que leva 0 estudante a refletir sobre qual seu papel na sociedade como futuro profissional e desta forma, media o processo de aprendizagem. ${ }^{21}$

Para que o estudante seja considerado apto ao exercício profissional, deve-se garantir o desenvolvimento das competências gerais durante sua formação. É fundamental que a formação favoreça aspectos relacionados aos conhecimentos específicos da área, que propicie o desenvolvimento de aspectos do trabalho cotidiano em sala de aula, que destaque metodologias e conteúdos. ${ }^{22}$

A escassa produção científica sobre competências na formação do nutricionista, bem como a falta de aprofundamento em estudos sobre a graduação em Nutrição, podem ter limitado a reflexão sobre a abordagem realizada. Considera-se que o presente estudo demonstra a realidade de uma parcela de escolas, pertencentes a um grupo com características próprias, que reflete a realidade local e pode não corresponder a Cursos em outras regiões. Porém, considera-se o presente estudo útil para toda comunidade acadêmica, bem como gerador de reflexões que podem auxiliar modificando o cenário atual da formação em Nutrição de forma a enfrentar os desafios da formação acadêmica.

\section{Conclusão}

Conclui-se que os graduandos dos cursos de Nutrição envolvidos na pesquisa não estão desenvolvendo as competências gerais necessárias à formação em sua totalidade. Considerando os diferentes momentos do curso, professores percebem estudantes nos anos finais do curso mais preparados que os estudantes nos anos iniciais.

$\mathrm{Na}$ visão dos professores, os estudantes avaliados desenvolvem mais as competências e habilidades de Gestão em saúde e Educação em saúde, enquanto na visão dos estudantes houve pequeno destaque apenas na Educação em saúde. Ao se comparar as instituições avaliadas, uma delas "Instituição A", apresentou melhor avaliação no desenvolvimento das competências na dimensão Educação em saúde.

A Nutrição tem um papel relevante na manutenção da saúde, prevenção de doenças, no tratamento e recuperação da saúde. Assim, é necessário avaliar o desenvolvimento de competências durante a graduação, uma vez que assim pode-se fomentar a discussão e a melhoria na graduação.

Novos estudos devem ser conduzidos no sentido de discutir e acompanhar a formação de graduandos em Nutrição no âmbito estadual e nacional, devido ao pequeno número de publicações na área específica.

\section{Contribuições dos autores}

\begin{abstract}
Ravazzani EDA participou do desenho do projeto, coleta de dados, análise e discussão dos resultados, escrita do artigo. Matia $G$ participou da análise e discussão dos resultados, escrita do artigo. Coelho IM participou da análise e discussão dos resultados, escrita do artigo. Esteve RZ participou do contribuiu com o desenho do projeto, análise e discussão dos resultados, escrita do artigo.
\end{abstract}

\section{Conflitos de interesses}

Nenhum conflito financeiro, legal ou político envolvendo terceiros (governo, empresas e fundações privadas, etc.) foi declarado para nenhum aspecto do trabalho submetido (incluindo mas não limitandose a subvenções e financiamentos, conselho consultivo, desenho de estudo, preparação de manuscrito, análise estatística, etc). 


\section{Referências}

1. Ministério da Educação (BR). Conselho Nacional de Educação. Diretrizes curriculares para o Curso de Nutrição: Resolução CNE/CES n 5, de 7 de novembro de 2001.

2. Gupta P, Dewan P, Singh T. Objective structured clinical examination (OSCE) revisited. Indian Pediatrics. 2010;47(11):911-920.

3. Albuquerque VS, Gomes AP, Rezende CHAS, Sampaio $M X$, Dias OV, Lugarinho RM. A integração ensino-serviço no contexto dos processos de mudança na formação superior dos profissionais da saúde. Rev bras educ med. 2008; 32(3):356362. doi: $10.1590 / 1413-812320172210.18102017$

4. Aguiar AC, Ribeiro ECO. Conceito e avaliação de habilidades e competência na educação médica: percepções atuais dos especialistas. Rev bras educ med. 2010; 34(3):371-378. doi: 10.1590/S0100$\underline{55022010000300006}$

5. Ricardo EC. Discussão acerca do ensino por competências: problemas e alternativas. Cad Pesqui. 2010;40(140):605628. doi: 10.1590/S0100-15742010000200015

6. Recine E, Mortoza ASM. Consenso sobre Habilidades e Competências do Nutricionista no ambito da Saúde Coletiva. Brasilia: Observatório de Politicas de Segurança e Nutrição; 2013.

7. Santos WS. Organização curricular baseada em competência na educação médica. Rev bras educ med. 2011 ;35(1):86-92. doi: 10.1590/S0100$\underline{55022011000100012}$

8. Tanaka OY. Avaliação da atenção básica em saúde: uma nova proposta. Saúde soc. 2011 ;20(4):927-934. doi: 10.1590/S0104-12902011000400010

9. Benito GAV, Tristão KM, Paula ACSF, Santos MA, Ataide LJ, Lima RCD. Desenvolvimento de competências gerais durante o estágio supervisionado. Rev bras enferm. 2012;65(1):172178. doi: $10.1590 /$ S0034-71672012000100025

10. Matia G. Desenvolvimento e validação de instrumento para avaliação das competências gerais nos cursos da área da saúde. [dissertação]. Curitiba: Faculdades Pequeno Príncipe; 2015.

11. Mitre $S M$, Siqueira RB, Girardi JMM, Morais NMP, Meirelles $C A B$, Pinto $C P$, et al. Metodologias ativas de ensinoaprendizagem na formação profissional em saúde: debates atuais. Ciênc saúde coletiva. 2008 dec;3(spul 2):2133-2144. doi: $10.1590 /$ S1413-81232008000900018

12. Baille E, Bjarnholt C, Gruber M, Hugles R. A capacitybuilding conceptual framework for public health nutrition practice. Public Health Hutrition. 2009;1 2(8):1031-1038. doi: $10.1017 /$ S1368980008003078
13. Oliveira FMCSN, Ferreira EC, Rufino NA, Santos MSS. Educação permanente e qualidade da assistência à saúde: aprendizagem significativa no trabalho da enfermagem. Aquichan. $2011 ; 11(1)$ :48-65.

14. Camelo SHH, Angerami ELS. Competência profissional: A construção de conceitos, estratégias desenvolvidas pelos serviços de saúde e implicações para a enfermagem. Texto Contexto Enferm. 2013;22(2):552-560. doi: 10.1590/ S0104-07072013000200034

15. Boog MCF. Atuação do nutricionista em saúde pública na promoção da alimentação saudável. Ciência \& Saúde. 2008;1:33-42. doi: 10.15448/1983-652X2008.1.3860

16. Recine $E$, Gomes RCF, Fagundes AA, Pinheiro ARO, Teixeira BA, Souza JS, et al. A formação em saúde pública nos cursos de graduação de Nutrição no Brasil. Rev Nutr. 2012;25(1);23-33. doi: 10.1590/S1415$\underline{52732012000100003}$

17. Anastasiou LGC. Metodologia ativa, avaliação, metacognição e ignorância perigosa : Elementos para reflexão na docência universitária. Revista espaço para a saúde. 2014 jun;15 (supl 1):18-34.

18. Nideck RLP, Queiroz PP. Perspectivas para o ensino na saúde: do "apagão educacional" à politica de Educação permanente. Trab educ saúde. 2015;13(1):159-180. doi: $10.1590 / 1981-7746-$ sip00022

19. Briccia V, Carvalho AMP. Competências e formação de docentes dos anos iniciais para a educação científica. Ens Pesqui Educ Ciênc. 2016;18:1-22. doi: 10.1590/198321172016180103

20. Nascimento DDG, Oliveira MAC. Reflexões sobre as competências profissionais para o processo de trabalho nos Núcleos de Apoio à Saúde da Família. O Mundo da Saúde. 2010;34(1):92-96.

21. Finkler M, Verdi MIM, Caetano JC, Ramos FRS. Formação profissional ética: um compromisso a partir das diretrizes curriculares? Trabalho, Educação e Saúde. 2010; 8(3):449462. doi: 1590/S1981-77462010000300007

22. Bergamo FVM, Ponchio MC, Zambaldi F, Giuliani AC, Spers EE. De prospect a aluno: fatores influenciadores da escolha de uma instituição de ensino superior. BASE: Revista de Administração e Contabilidade da Unisinos. 2010;7(3):182-193. 